\title{
Aggravated mucosal and immune damage in a mouse model of ulcerative colitis with stress
}

\author{
YANXIA GONG $^{1 *}$, WEI NIU ${ }^{1 *}$, YANPING TANG ${ }^{1}$, QINGYU ZHANG ${ }^{2}$, SIMIAO LIU $^{1}$, \\ $\mathrm{XI} \mathrm{LIU}^{1}, \mathrm{XIAO} \mathrm{WANG}^{3}$ and YANG XU${ }^{1}$ \\ ${ }^{1}$ Department of Gastroenterology, Tianjin Nankai Hospital, Tianjin 300100; \\ ${ }^{2}$ Department of Gastroenterology, Tianjin Medical University General Hospital, Tianjin 300052; \\ ${ }^{3}$ Department of Oncology, Hebei Provincial Hospital of Traditional Chinese Medicine, \\ Shijiazhuang, Hebei 050011, P.R. China
}

Received February 9, 2018; Accepted October 26, 2018

DOI: $10.3892 /$ etm.2019.7162

\begin{abstract}
The aim of the present study was to determine the influence of stress on the colonic mucosa and immune system and to further investigate the association between stress and development and pathogenesis of ulcerative colitis (UC). Mice were treated with 2,4,6-trinitrobenzenesulfonic acid to induce an animal model of UC, and stress was induced by water immersion and restraint. Subsequently, the disease activity index (DAI), secretory immunoglobulin $\mathrm{A}(\mathrm{sIg}$ A), $\operatorname{Ig} \mathrm{A}$, interleukin (IL)- 6 and -8 , tumor necrosis factor- $\alpha$ (TNF- $\alpha$ ), complement component (C) 3 and $\mathrm{C} 4$, and alterations in the colonic mucosa were observed. The DAI scores and the expression levels of IL-6, IL- 8 and TNF- $\alpha$ significantly increased in the experimental UC mice compared with the control mice, while the expression levels of $\operatorname{Ig} \mathrm{A}$ and $\operatorname{sIg} \mathrm{A}$ decreased (all $\mathrm{P}<0.01)$. DAI and colonic mucosa damage scores increased in the stress-treated mouse models of UC compared with the untreated mouse models of UC $(\mathrm{P}<0.05)$. Expression levels of $\operatorname{Ig} \mathrm{A}$ and $\operatorname{sIg} \mathrm{A}$ decreased, while IL-6, IL- 8 and TNF- $\alpha$ further increased in the stress-treated UC mice $(\mathrm{P}<0.05)$. The expression levels of $\mathrm{C} 3$ and $\mathrm{C} 4$ were not affected by stress or UC $(\mathrm{P}>0.05)$. These results indicated that UC may be associated with an immune disorder and that stress can aggravate colonic mucosa injury and alter the immune response. Furthermore, stress and immunity may serve roles in the pathogenesis of UC.
\end{abstract}

Correspondence to: Professor Yanping Tang or Dr Yanxia Gong, Department of Gastroenterology, Tianjin Nankai Hospital, 122 Nankai Sanwei Road, Tianjin 300100, P.R. China

E-mail: cb1699@sina.com

E-mail: gong_yanxia@aliyun.com

${ }^{*}$ Contributed equally

Key words: ulcerative colitis, mice, stress, mucosa, immune response, injury

\section{Introduction}

Ulcerative colitis (UC), an inflammatory bowel disease (IBD) affecting the colon, is characterized by a chronic, relapsing, organ-specific inflammatory state of the mucosa (1). The incidence and prevalence of UC are higher in countries with greater economic development, particularly in the northern countries of Western Europe, Canada, USA, Australia and New Zealand (2). The incidence of UC has recently increased (3). The pathogenesis of UC is associated with various factors, including genetic predisposition (4), environmental risk factors (5) and the state of the immune system (6). Furthermore, the disorder of the immune system is considered an important factor (7), and psychological stress is considered one of the risk factors for UC (8).

The recent increase in the pace of human life, competition, pollution and the number of stress stimuli contributed to greater susceptibility to disease. Research into the influence of stress on disease status has received increasing attention from clinicians. Stress causes alterations in psychological and physiological functions due to recognition and evaluation of the stimuli from a stress source (9). The mechanism by which psychological factors influence the body has not been extensively studied. It is challenging to design experiments to quantitatively measure psychological factors and evaluate psychosomatic associations. However, animal models of stress have been previously established and used to study physiological responses (10). Therefore, the present study aimed to observe the effects of stress on the general condition, characteristics of the colonic mucosa and immunity-associated indicators of normal control mice and mouse models of UC mice. In addition, the present study investigated the effect of stress on the occurrence, development, prognosis and possible pathogenesis of UC.

\section{Materials and methods}

Materials. Mice were weighed $1 \mathrm{~h}$ before the initiation of the model, and a calculation was made to obtain a 5\% 2,4,6-trinitrobenzenesulfonic acid solution (TNBS; $150 \mathrm{mg} / \mathrm{kg}$; Sigma-Aldrich, Merck KGaA, Darmstadt, Germany). The 
final solution was mixed to achieve a solution of 5\% TNBS and $380 \mathrm{~g} / \mathrm{l}$ ethanol using a 4:1 volume ratio of ethanol to TNBS.

The laboratory equipment used in the present study included a LabSystems Multiskan MS plate reader (Thermo Labsystems, Helsinki, Finland), anesthesia machine (Beijing Yiren Hengye Technology Co. Ltd, Beijing, China), optical microscope (Olympus Corporation, Tokyo, Japan), water jacketed incubator (Shanghai Yiheng Scientific Instruments, Co., Ltd., Shanghai, China) and gavage needles (Changzhou Jinliyuan Medical Instrument Co. Ltd, Changzhou, China). Enzyme-linked immunosorbent assay (ELISA) kits for secretory (s) immunoglobulin (Ig)A (SBJ-R0054), interleukin (IL)-6 (SBJ-H0465), IL-8 (SBJ-R0033), tumor necrosis factor (TNF)- $\alpha$ (SBJ-R0040), complement component (C)3 (SBJ-H0199) and C4 (SBJ-R0368) were obtained from SBJBio (Nanjing, China), and the ELISA kit for IgA (FU-D1033) was obtained from Beijing Xin Fangcheng Biotechnology Co., Ltd. (Beijing, China).

Animals. A total of 80 experimental specific pathogen-free BALB/c mice (age, 6-8 weeks; weight, 18-22 g) were purchased from the Institute of Laboratory Animal Science, Chinese Academy of Medical Sciences (Beijing, China). Mice were maintained at a specific pathogen-free facility with $40-70 \%$ humidity and $24-26^{\circ} \mathrm{C}$ temperature, with a 12 -h light/dark cycle and free access to food and water. The research program was approved by the Ethics Committee of Tianjin Nankai Hospital. The mice were allowed to acclimate to laboratory conditions for 7 days and then fasted for $36 \mathrm{~h}$ with ad libitum access to water. The mice were subsequently deprived of water $1 \mathrm{~h}$ before the experiment and randomly divided into 4 groups ( $n=20 /$ group): i) Control group (A); ii) stress group (B), iii) $\mathrm{UC}+$ stress group (C); and UC model alone (D). Mice in groups $\mathrm{C}$ and $\mathrm{D}$ were treated with TNBS-ethanol solution to induce UC. After 5 days, the mice in groups $\mathrm{B}$ and $\mathrm{C}$ were restrained in water, as described below.

\section{Establishment of the animal model}

Establishment of the animal model of UC. The present study used a modified TNBS protocol combined with an addition of an alcohol complex to establish the animal model of UC (11). Mice were fasted for $36 \mathrm{~h}$ with free access to water. Animals were subsequently weighed $1 \mathrm{~h}$ before the experiment in order to calculate the drug dose to be administered and were anaesthetized by isoflurane inhalation, as previously described (anesthesia machine oxygen flow rate, $0.6 \mathrm{nl} / \mathrm{min}$; isoflurane concentration, 4-6\%; maintenance anesthesia, isoflurane 1-2\% for 1 min using an anesthesia tube and plastic funnel to cover the nose and mouth of the mice) (12). Anesthesia was considered successful when the mice were calm, supine and breathing smoothly. For administration of the TNBS-ethanol solution, a gavage needle was connected to a 1-ml syringe. The needle was lubricated with liquid paraffin and slowly inserted into the anus of each mouse to a depth of $\sim 1-2 \mathrm{~cm}$. The solution was slowly injected with the gavage needle continuously pushed. The solution was completely injected at a depth of 4-5 cm into the anus. The tail of the mouse was slowly lifted to clench the anus to prevent the outflow of liquid and in order to ensure that the TNBS solution was dispersed in the colon. In addition, the anesthesia table and the mice were maintained at angle of $45-60^{\circ} \mathrm{C}$ and the position of the mice was rotated for $5 \mathrm{~min}$ to ensure that the TNBS solution was in contact with the wall of the colon. The mice naturally woke and became alert, and were subsequently released into the cages and provided free access to food and water. Measurements were taken 5 days following induction of the model of UC.

Establishment of the animal model of stress. Groups B and $\mathrm{C}$ were subjected to stress via the water immersion restraint method. Mice were fasted for $24 \mathrm{~h}$ with ad libitum access to water. Mice were anaesthetized in a cage and immersed in water continuously for $4 \mathrm{~h}$ (water temperature, $25 \pm 1^{\circ} \mathrm{C}$; water level, cartilago ensiformis) as previously described (13).

General condition of the mice. The following characteristics of mice were observed and recorded: Mental state (via duration of sleep, time of waking and response to external stimuli), physical activity (14), food consumption, body weight, fur gloss (15), stool type, fecal occult blood and mortality rate. The disease activity index (DAI) was calculated as previously described by Murthy et al (16) (Table I), using the following formula: DAI=[weight loss $(\%)+$ characterization of feces + hematochezia) $/ 3$.

Macroscopic scores. Mice were restrained and blood samples were collected via orbital puncture following anesthesia as described above. Mice were euthanized by cervical dislocation and dissected to open the abdominal cavity and access the colon. Colonic lavage was performed. Following removal of the colon lavage fluid and brushing of intestinal tissue, the colon was cut into sections along the mesenteric side and fixed with a pin. The colon was subsequently observed by the naked eye and scored according to the criteria described in Table II $(17,18)$.

Microscopic scores. Distal colon sections $(0.5 \mathrm{~cm}$ from the anus; dimensions, $1 \times 0.5 \mathrm{~cm}$ ) were obtained for analysis, fixed with $4 \%$ formalin at room temperature for $24 \mathrm{~h}$, and embedded in paraffin. Subsequently, 4- $\mu \mathrm{m}$-thick sections were prepared and hematoxylin-eosin staining was performed at room temperature. For each slice, 3 fields of view were randomly selected for analysis and scored according to the parameters previously described by Gaudio et al (19) (Table III).

Detection of immune factors. Following the induction of the animal model of stress, mice were dried off to prevent water from contaminating the microcentrifuge tubes and causing hemolysis. Following blood collection for detection of immunoglobulin (Ig)A, interleukin (IL)-6, IL-8, TNF- $\alpha$, C3 and C4 by orbital puncture, mice were sacrificed, and the abdominal cavity was dissected to isolate the colon, as detailed above, which was subsequently washed thrice with $2 \mathrm{ml}$ physiological saline. The saline was removed, and the solution was centrifuged for $20 \mathrm{~min}$ at $4^{\circ} \mathrm{C}(1,369.5 \mathrm{x} \mathrm{g})$. The supernatant was removed to detect soluble (s)IgA. All samples were processed using ELISA kits, according to the manufacturer's protocol.

Statistical analysis. Data are presented as the mean \pm standard deviation. Differences between any 2 groups were determined by one-way analysis of variance with the Student-Newman-Keuls 
Table I. Disease activity index scores.

\begin{tabular}{lccc}
\hline Score & $\begin{array}{c}\text { Weight } \\
\text { loss }(\%)\end{array}$ & $\begin{array}{c}\text { Characterization } \\
\text { of feces }\end{array}$ & Hematochezia \\
\hline 0 & 0 & Normal & Negative \\
1 & $1-5$ & - & - \\
2 & $6-10$ & Semi-loose & Occult blood (+) \\
3 & $11-15$ & - & - \\
4 & $>15$ & Loose & $\begin{array}{l}\text { Bloody visible } \\
\text { by naked eye }\end{array}$ \\
\hline
\end{tabular}

Table II. Macroscopic scores of the colonic mucosa.

\begin{tabular}{|c|c|}
\hline Score & Alterations in colonic mucosa \\
\hline 0 & No damage \\
\hline 1 & Mucosal hyperemia, edema, no ulcer \\
\hline 2 & Mucosal hyperemia, edema, mild erosion, no ulcer \\
\hline 3 & $\begin{array}{l}\text { Mucosal hyperemia, edema, moderate erosion, } \\
\text { single ulcer }\end{array}$ \\
\hline 4 & $\begin{array}{l}\text { Mucosal hyperemia, edema, severe erosion, multiple } \\
\text { ulcers }\end{array}$ \\
\hline 5 & $\begin{array}{l}\text { Mucosal hyperemia, edema, severe erosion, } \\
\text { ulcer }>1 \mathrm{~cm}\end{array}$ \\
\hline
\end{tabular}

post hoc test. SPSS software (version 16.0; SPSS, Inc., Chicago, IL, USA) was used for all calculations. $\mathrm{P}<0.05$ was considered to indicate a statistically significant difference.

\section{Results}

General condition of the mice. Following $36 \mathrm{~h}$ of fasting with ad libitum access to water, the maximum body weight loss of mice was $1.06 \mathrm{~g}$. The rage of weight loss was $0.85 \pm 0.21 \mathrm{~g}$. The following observations were made regarding the general condition of group A mice: Glossy fur, responsive to stimuli, physically active and flexible, healthy weight and granular stool. In comparison with group $\mathrm{A}$, mice in groups $\mathrm{C}$ and $\mathrm{D}$ exhibited slow activity, increased duration of sleeping, loose and dull skin, decreased appetite, bloody stool and weight loss (Fig. 1). Mice in group B exhibited excitability, and increased breathing and heart rate in the early stage of the stress experiment. These mice gradually became subdued with smooth breathing and reduced responses to external stimuli. Group C mice exhibited similar characteristics to group B mice but their excitement (physical activity, propensity to cry and struggle when being handled) intensity was weaker and more rapidly suppressed. Preoperative DAI values for the mice in each group exhibited no significant differences $(\mathrm{P}>0.05)$. The DAI values of each group at 5 days post-administration of TNBS-ethanol solution were in the following order from high to low: $C>D>B>A$. There was a statistically significant difference between group $A$ and both groups $\mathrm{C}$ and $\mathrm{D}(\mathrm{P}<0.01)$. Furthermore, the DAI index
Table III. Ulcerative colitis pathological scoring standard.

Pathological morphology Score

Destruction of epithelium and glands

Morphologically normal

Focal destruction of the epithelial surface

and/or focal crypt dropout

Zonal destruction of the epithelial surface

and/or zonal crypt loss

Diffuse and/or mucosal ulceration involving

submucosa and/or diffuse crypt losses

Dilatation of glandular crypts

Normal

Focal dilatation

1

Zonal dilatation

2

Dilated crypts

Depletion and loss of goblet cells

Normal

Slightly depleted goblet cells

Zonal or moderately depleted goblet cells

Diffusely or completely depleted goblet cells

Inflammatory cell infiltration

Absence of infiltrate

Infiltrate at the subepithelial and lamina propria

level or crypt bases

Infiltrate reaching muscularis mucosae

Severe and extensive infiltrate reaching

submucosa and/or involving muscularis propria

Edema

Absent

Focal

Zonal and/or moderately diffuse

Extensive or severe

Vascular congestion

$\begin{array}{ll}\text { Absent } & 0 \\ \text { Focal } & 1 \\ \text { Zonal } & 2 \\ \text { Diffuse } & 3\end{array}$

Crypt abscesses

Absent 0

Focal 1

Zonal 2

Diffuse 3

Atrophia

Absent 0

Focal 1

Zonal 2

Diffuse 3

in group B was different compared with both groups $\mathrm{C}$ and $\mathrm{D}(\mathrm{P}<0.01)$. DAI scores were not significantly different between groups $\mathrm{C}$ and $\mathrm{D}$ ( $\mathrm{P}>0.05$; Fig. 1$)$. No mortality was 
A
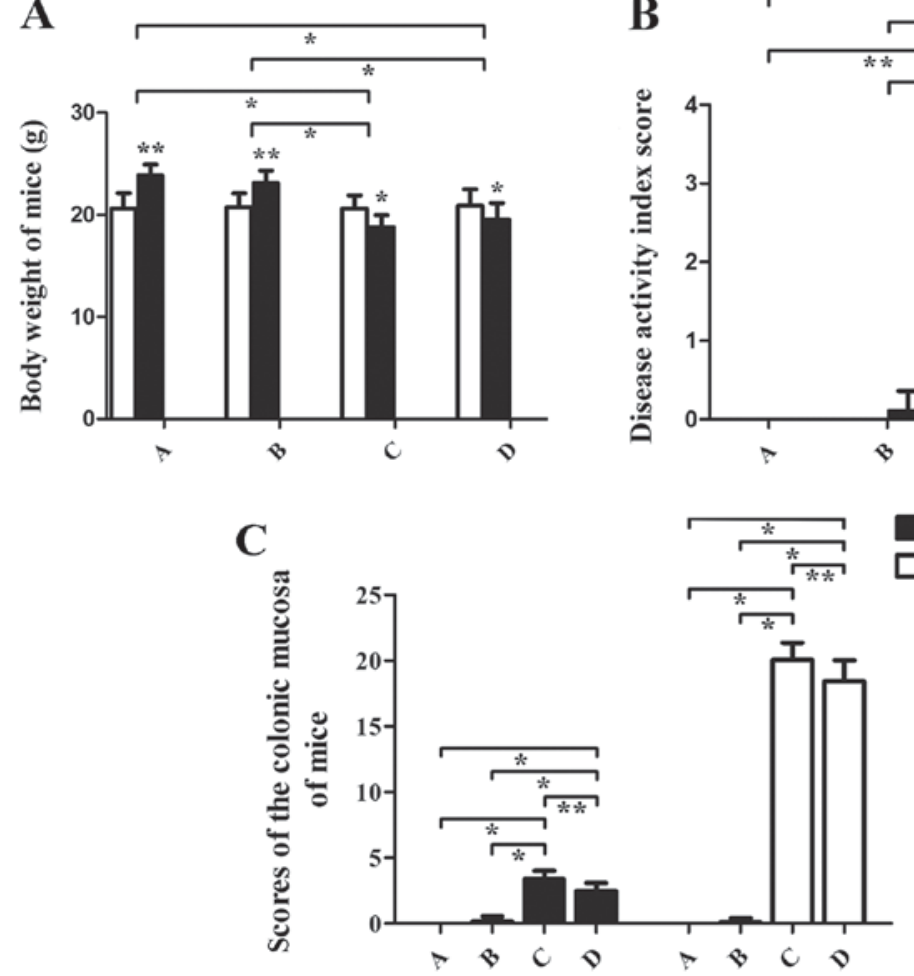

Figure 1. Body weight, disease activity index score and mucosa macroscopic and microscopic scores of mice. (A) The body weight of mice. (B) The disease activity index score score in group A, B, C and D. TNBS-ethanol solution was only administered in groups C and D (Establishment of the animal model of UC with TNBS-ethanol solution ). (C) The macroscopic and microscopic scores of the colonic mucosa of mice. A (control group), B (stress group), C (UC and stress group), D (UC model alone). ${ }^{*} \mathrm{P}, 0.05,{ }^{* *} \mathrm{P}<0.01$. UC, ulcerative colitis.

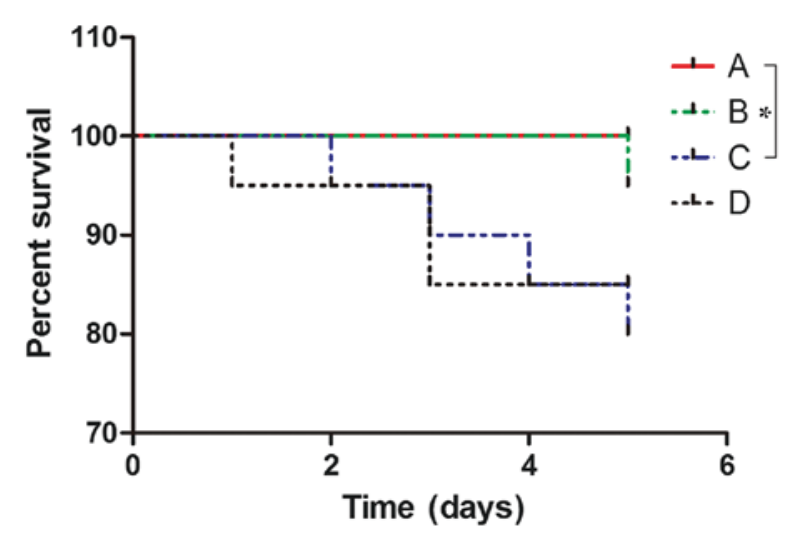

Figure 2. Survival conditions of mice. A, control group; B, stress group; $\mathrm{C}$, UC and stress group; D, UC model alone. The results demonstrated that the survival of mice after administration of TNBS-ethanol solution in group $\mathrm{C}$ was lower than group $\mathrm{A}(\mathrm{P}=0.0455)$. However, there were no significant differences among groups B, C and D. UC, ulcerative colitis.

observed in group A. Mortality was observed in one mouse in group $\mathrm{B}$ due to asphyxia; 4 in group $\mathrm{C}$, including 2 from intestinal necrosis, 1 from mechanical intestinal obstruction and 1 from asphyxia; and 3 in group D, including 1 case of mortality due to intestinal necrosis and 2 due to mechanical intestinal obstruction (Fig. 2). The survival of mice in group A was better than that ingroup $\mathrm{C}$, and the difference was statistical significant $(\mathrm{P}=0.0455)$. However, there was no significant difference in survival among groups B, C and D at day 5 .
Macroscopic and microscopic characteristics of the colonic mucosa. Macroscopic characteristics were evaluated by the naked eye. Normal colonic mucosa should appear red and smooth with no injury, as in group A. However, following induction of the UC model, colonic mucosa became extensively congested and edema and ulcers were observed along with the development of rough mucus membrane with mucosal erosion, which was obvious in group C. Group B had a less marked manifestation than group C (Fig. 3).

Pathological analysis using microscopy indicated inflammatory cell infiltration, diffuse mucosal hyperaemia, extensive edema, epithelial and glandular damage, decreased number of goblet cells, and crypt abscesses (Fig. 4). Groups B, C and D had different degrees of injury. Among them, group $\mathrm{C}$ was the most severe. The above results indicated that stress can aggravate injury of the colonic mucosa (Figs. 1, 3 and 4).

Serum levels of IgA and secretory sIgA in colonic lavage fluid. The levels of serum IgA and $\operatorname{sgA}$ in the colonic lavage fluid of each group 5 days post-administration were in the following order from the highest to the lowest: $A>B>D>C$. Statistically significant differences were identified between groups $A$ and $\mathrm{C}(\mathrm{P}<0.01)$, and groups $\mathrm{B}$ and $\mathrm{C}(\mathrm{P}<0.01)$. In comparison with group $\mathrm{D}$, the level of group $\mathrm{C}$ was also declined $(\mathrm{P}<0.05$; Fig. 5).

Serum levels of IL6, IL8,TNF- $\alpha, C 3$ and $C 4$. The serum levels of IL6, IL8, TNF- $\alpha, \mathrm{C} 3$ and C4 in each group 5 days post-administration were in the following order from the highest to the lowest: $C>D>B>A$. Significant differences 

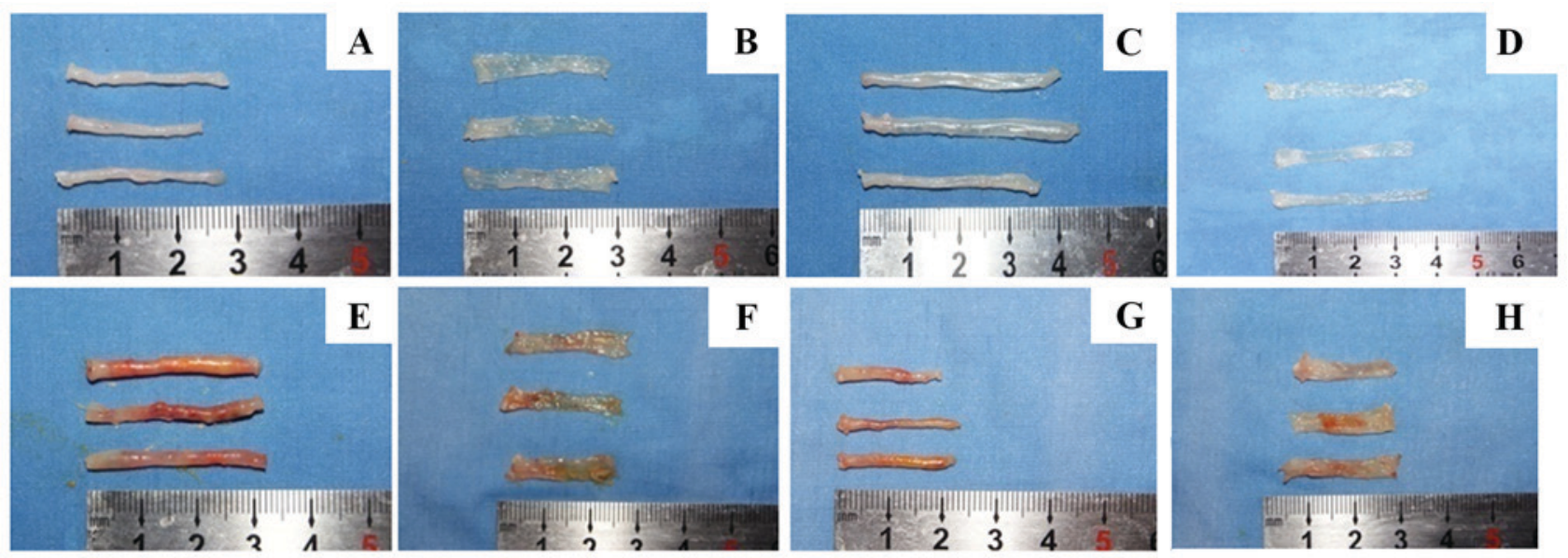

Figure 3. Macroscopic appearance of the colonic mucosa. (A) The external appearance of colonic tissue after excision in group A. (B) Section mucosal appearance of colonic tissue after incision in group A. (C) External appearance of colonic tissue after excision in group B. (D) Section mucosal appearance of colonic tissue after incision in group B. (E) External appearance of colonic tissue after excision in group C. (F) The section mucosal appearance of colonic tissue after incision in group C. (G) The external appearance of colonic tissue after excision in group D. (H) Section mucosal appearance of colonic tissue after incision in group D.
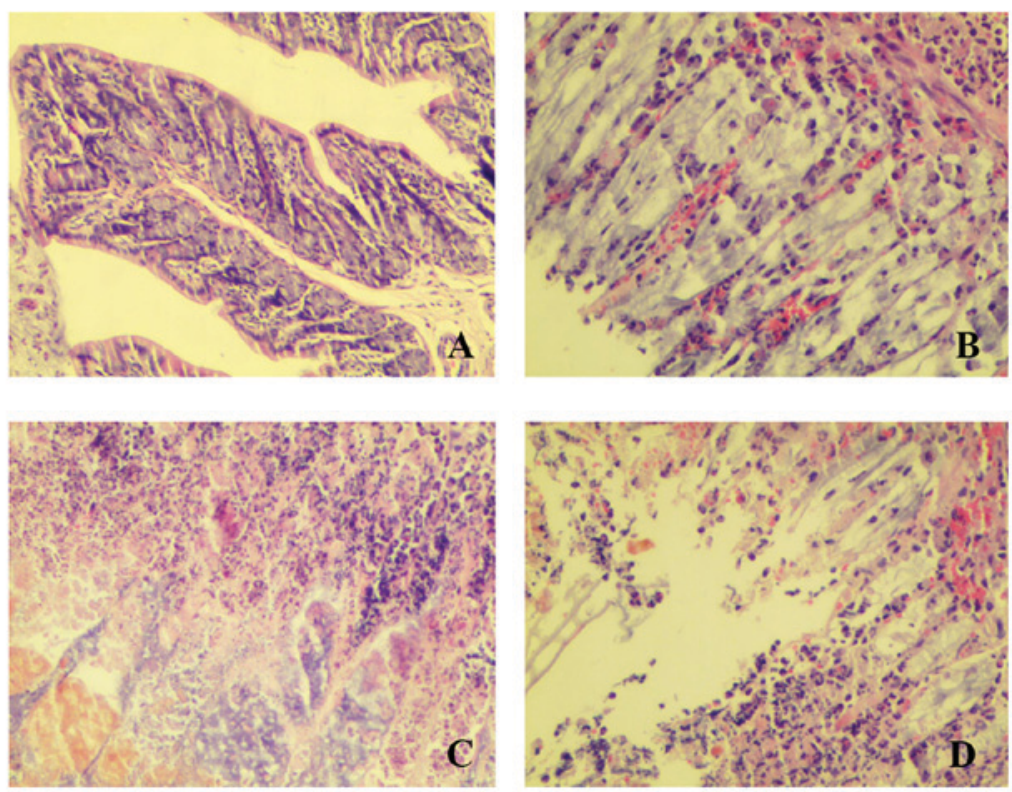

Figure 4. The microscopic appearance of the colonic mucosa. (A) control group; (B) stress group; (C) UC and stress group; (D) UC model alone. Observed under inverted microscopy at X200 magnification. UC, ulcerative colitis.

were observed in IL-6, IL-8 and TNF- $\alpha$ expression between groups $\mathrm{A}$ and $\mathrm{C}$, and between groups $\mathrm{B}$ and $\mathrm{C}(\mathrm{P}<0.01)$. Group $C$ exhibited higher levels than group $\mathrm{D}(\mathrm{P}<0.05$; Fig. 5). However, there was no significant difference in the levels of $\mathrm{C} 3$ and $\mathrm{C} 4$ between groups.

\section{Discussion}

UC is an immune-mediated chronic inflammatory disease with symptoms including abdominal pain, bloody diarrhea and fatigue. UC is associated with numerous complications involving all systems of the body and its chronic nature follows an unpredictable course with instances of exacerbation and remission (20). In recent years, it has become an increasingly common disease of the digestive system. With increasing incidence, UC can severely affect the physical and mental health, and the quality of life of patients (21). Previous studies indicated that UC may be associated with a complex interaction of genetic, environmental, immune and psychological factors in susceptible individuals. The interaction between these factors results in severe intestinal inflammation (22). Psychological effects from UC and UC medications are experienced by many patients with UC (23).

Adaptation to environmental stimuli is necessary to maintain homeostasis. Stress can be defined as a threat to an organism's homeostasis (8). Psychological stress is defined as a psychological alteration resulting from patients' feelings of unease, worry, and/or fear. Psychological stress induces gastrointestinal symptoms, including dyspepsia and abdominal pain $(24,25)$, and increased colonic motility (26). Stress 

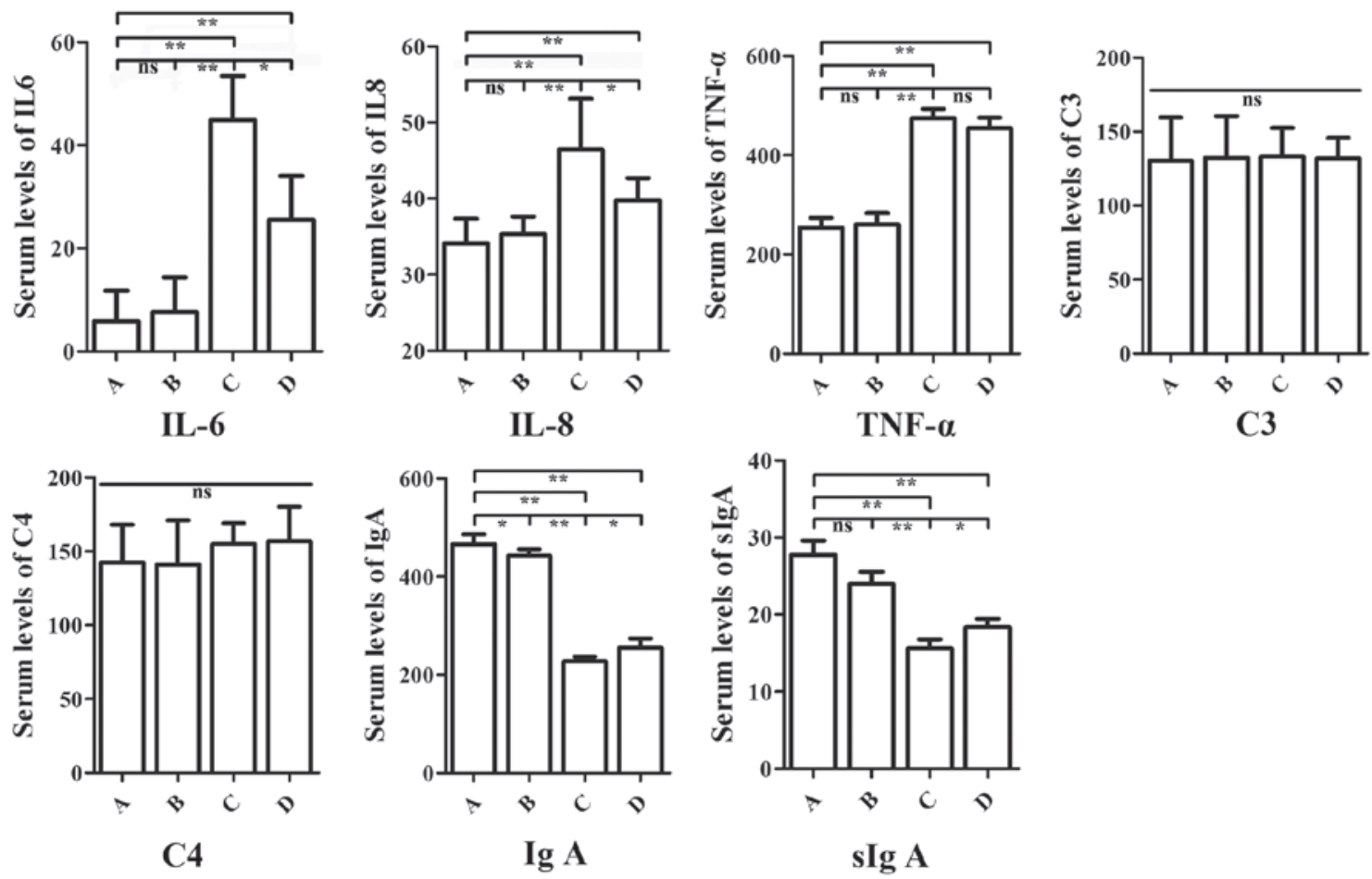

Figure 5. The serum expression levels of IL-6, IL-8, TNF- $\alpha$, C3, C4, IgA and $\operatorname{sg}$ A in different groups. A, control group; B, stress group; C, UC and stress group; D, UC model alone. "P, $0.05,{ }^{* *} \mathrm{P}<0.01$. IL, interleukin; TNF, tumor necrosis factor; Ig, immunoglobulin; s, soluble; $\mathrm{C}$, complement component; ns, not significant.

is a risk factor, trigger and perpetuating factor in UC (27). Mechanisms by which stress affects the nervous system to alter the immune function at both the systemic and gut mucosal level are currently under investigation $(28,29)$.

The results of the present study indicated that stress can aggravate the injury of the colonic mucosa and immune system. The effects of stress are complex and depend on the duration and intensity of the stimulus. A small amount of stress has been hypothesized to enhance immune function; however, increased intensity of stress can be detrimental due to excessive production of neuroendocrine-derived mediators that weaken immune responses to invasive pathogens (30). By acting on the catecholamine receptors of immune cells, stress may reduce the capacity of the sympathetic nervous system to release large amounts of catecholamines, thereby weakening the immune response (31). In addition, stress can cause intestinal motility dysfunction and intestinal flora imbalance, and induce spasms of intestinal smooth muscles and vessels, thus leading to a lack of blood and oxygen supply and an increase in mucosal barrier dysfunction (32).

Stress may be classified into 4 types, including physical, social, cultural and psychological (33). Among these, psychological stress is one of the most ubiquitous and notable (34). A number of experimental methods have been previously used to induce animal models of stress, including restraint, water immersion, thermal stress and fatigue $(35,36)$. Among these methods, the former two lead to pronounced stress and exhibited numerous advantages, including simplicity and low variability among different groups (10,37). Furthermore a combination of restraint and water immersion can successfully induce experimental anxiety to study the underlying psychological or emotional factors (38).
The mouse models of UC established in the present study consumed less food, exhibited decreased activity, weight loss, diarrhea, bloody stool, a decrease in fur glossiness, edema in colonic mucosa, congestion and ulcer formation, as observed by the naked eye. Furthermore, these mice exhibited infiltration of inflammatory cells, loss of goblet cells and ulcer formation, as exhibited by pathological analysis. All of the above parameters suggested that the model of UC was successfully induced. In addition, stress induced a decline in the general condition (mental state, activity, food consumption, body weight and fur gloss), an increase in DAI scores of mice with UC and aggravated macroscopic and microscopic damage of the colonic mucosa. These results indicated that stress may be a pathogenic factor for patients with UC and can result in disease exacerbation. Stress treatment, such as anti-anxiety therapy, may be a part of a comprehensive treatment strategy for patients with UC.

Healthy intestinal mucosa is protected against external stimuli by a complex mucosal defense barrier (39). In mouse models of UC, the colon mucosa was thin and extensively congested with edema and ulcers, which may be due to the defects of the intestinal barrier function and immune mechanisms (40).

Compared with the control group, the level of serum $\operatorname{Ig} \mathrm{A}$ and colonic lavage fluid $\operatorname{sIg} \mathrm{A}$ in the mouse models of UC with stress decreased significantly, demonstrating that stress produced the downward trend. Previous studies have reported a reduction in sIgA levels in patients with IBD, which is supported by the results of the present study (41). IgA and $\operatorname{sIg} \mathrm{A}$ are the most abundant Igs in humans and the first line of specific immunological defense against environmental antigens (42). Possible reasons for the decreased levels of $\operatorname{IgA}$ in 
mouse models of UC with stress are that the stress acted on the neuroendocrine immune regulation network, which decreased the release of large amounts of catecholamines by the sympathetic nerves, whereas catecholamines acted on catecholamine receptors of immune cells to weaken the body's immunity (43). Alternatively, stress may act through stimulating the release of glucocorticoids by the pituitary adrenal cortex system of the brain to induce immune suppression (44). Immune suppression in addition to the weakened colonic mucosal barrier function, may cause reduced resistance to external stimulation and aggravated severity of UC (45). This abnormal intestinal immune response may be involved in the pathogenesis of UC.

TNF- $\alpha$ is an important proinflammatory cytokine associated with cell apoptosis, inflammation, metabolism and thrombosis. TNF- $\alpha$ stimulates the secretion of IL- 6 and -8 to promote the activation of nuclear factor (NF)- $\kappa \mathrm{B}$, which induces proinflammatory and immunomodulatory gene expression (46). Active $\mathrm{NF}-\kappa \mathrm{B}$ can further stimulate the expression of TNF- $\alpha$ and increase the intensity of inflammation (47). The development of neuroendocrine immunology introduces a new perspective for understanding the mechanisms underlying stress (48). Stress can activate the peripheral and central immune system responses and induce the release of inflammatory mediators, including TNF- $\alpha$, IL-6 and IL-8 (49). Activated immune system mediates the process of psychological disorder through the interaction with neuronal and neuroendocrine systems (50). An animal model of UC used in the present study exhibited significantly increased serum IL-6, IL- 8 and TNF- $\alpha$ expression levels. It has been previously demonstrated that stress may lead to neuroendocrine immune system abnormalities that increase the secretion of IL- 6 , IL- 8 and TNF- $\alpha$. Therefore, it may be hypothesized that in the present study, stress exacerbated UC due to increased secretion of IL-6, IL- 8 and TNF- $\alpha$ via the neuroendocrine-immune system.

Serum C3 and C4 serve important roles in immune defense, immune regulation, and immune pathology. Decreased expression levels of these factors may cause a decreased ability to resist external pathogens and increased susceptibility to illness (51). In the present study, induction of the UC model and stress exhibited no significant effects on serum levels of $\mathrm{C} 3$ and $\mathrm{C} 4$, and the reason may be associated with insufficient sample size or the type of stress and the duration of stimulation. Alternatively, stress may have no effect on $\mathrm{C} 3$ and $\mathrm{C} 4$; however, further studies are required to test this hypothesis.

Using the water immersion with restraint method of stress induction, the present study concluded that stress may increase colonic mucosa damage in mice with UC and interfere with the immune regulation involving TNF- $\alpha, \operatorname{Ig} \mathrm{A}, \operatorname{sIg} \mathrm{A}, \mathrm{C} 3$ and $\mathrm{C} 4$, thereby increasing the severity of UC in mice. The above data suggested that, at least in some UC mice, stress may reflect primary disease activity via immune damage, and that it is possible that stress treatment rather than etiological and medical treatment would be more effective. Psychological stress is common among patients with UC and can lead to reduced quality of life (52). Given the association between UC and stress, clinicians may consider the treatment of stress is an integral part of therapies for patients with UC.

The present study has certain limitations. First, an animal model was used for exposure to a stress-inducing environment. The experiment should be continued following the elimination of the stress environment to evaluate the change of colonic mucosa and serum levels of IgA, IL-6, IL-8, TNF- $\alpha$, C3 and $\mathrm{C} 4$. Furthermore, the underlying mechanism of action of stress in the development of UC remains to be elucidated. The mechanism of stress in the progression of UC requires further investigation. Future studies should investigate the association between stress and the nervous, endocrine, and immune systems in the context of the pathogenesis of UC.

\section{Acknowledgements}

Not applicable.

\section{Funding}

The present study was supported by the Tianjin Foundation of Science and Technology (grant no. 2013KY25).

\section{Availability of data and materials}

The datasets used and/or analyzed during the current study are available from the corresponding author on reasonable request.

\section{Authors' contributions}

YG and YT were responsible for the conception and design of the study. WN, XW, QZ and YX assisted in animal experiments. YG, SL and XL assisted in the ELISA and immunohistochemistry assays. YG, YT and QZ wrote, reviewed and revised the manuscript. All authors participated in final approval of the manuscript.

\section{Ethics approval and consent to participate}

The research program was approved by the Ethics Committee of Tianjin Nankai Hospital (Tianjin, China).

\section{Patient consent for publication}

Not applicable.

\section{Competing interests}

The authors declare that they have no competing interests.

\section{References}

1. DeRoche TC, Xiao SY and Liu X: Histological evaluation in ulcerative colitis. Gastroenterol Rep 2: 178-192, 2014.

2. Parente JM, Coy CS, Campelo V, Parente MP, Costa LA, da Silva RM, Stephan C and Zeitune JM: Inflammatory bowel disease in an underdeveloped region of Northeastern Brazil. World J Gastroenterol 21: 1197-1206, 2015.

3. Shivashankar R, Tremaine WJ, Harmsen WS and Loftus EV Jr: Incidence and prevalence of crohn's disease and ulcerative colitis in olmsted county, minnesota from 1970 through 2010. Clin Gastroenterol Hepatol 15: 857-863, 2017.

4. Kabi A, Nickerson KP, Homer CR and McDonald C: Digesting the genetics of inflammatory bowel disease: Insights from studies of autophagy risk genes. Inflamm Bowel Dis 18: 782-792, 2012.

5. Guo AY, Stevens BW, Wilson RG, Russell CN, Cohen MA, Sturgeon HC, Thornton A, Giallourakis C, Khalili H, Nguyen DD, et al: Early life environment and natural history of inflammatory bowel diseases. BMC Gastroenterol 14: 216, 2014. 
6. Vadasz Z, Rainis T, Nakhleh A, Haj T, Bejar J, Halasz K and Toubi E: The involvement of immune semaphorins in the pathogenesis of inflammatory bowel diseases (IBDs). PLoS One 10: e0125860, 2015

7. Cătană CS, Berindan Neagoe I, Cozma V, Magdaș C, Tăbarăn F and Dumitrascu DL: Contribution of the IL-17/IL-23 axis to the pathogenesis of inflammatory bowel disease. World J Gastroenterol 21: 5823-5830, 2015.

8. Mawdsley JE and Rampton DS: Psychological stress in IBD: New insights into pathogenic and therapeutic implications. Gut 54: 1481-1491, 2005.

9. Guo J, Mrug S and Knight DC: Emotion socialization as a predictor of physiological and psychological responses to stress. Physiol Behav 175: 119-129, 2017.

10. Pohl CS, Medland JE and Moeser AJ: Early-life stress origins of gastrointestinal disease: Animal models, intestinal pathophysiology, and translational implication. Am J Physiol Gastrointest Liver Physiol 309: G927-G941, 2015.

11. Majewska-Szczepanik M, Góralska M, Marcińska K, Zemelka-Wiącek M, Strzępa A, Dorożyńska I and Szczepanik M: Epicutaneous immunization with protein antigen TNP-Ig alleviates TNBS-induced colitis in mice. Pharmacol Rep 64: $1497-1504,2012$

12. Hohlbaum K, Bert B, Dietze S, Palme R, Fink H and Thöne-Reineke C: Severity classification of repeated isoflurane anesthesia in C57BL/6JRj mice - Assessing the degree of distress. PLoS One 12: e0179588, 2017.

13. Li YM, Lu GM, Zou XP, Li ZS, Peng GY and Fang DC: Dynamic functional and ultrastructural changes of gastric parietal cells induced by water immersion-restraint stress in rats. World J Gastroenterol 12: 3368-3372, 2006.

14. Horvath G, Kekesi G, Petrovszki Z and Benedek G: Abnormal motor activity and thermoregulation in a schizophrenia rat model for translational science. PLoS One 10: e0143751, 2015.

15. Sharpley CF, McFarlane JR and Slominski A: Stress-linked cortisol concentrations in hair: What we know and what we need to know. Rev Neurosci 23: 111-121, 2011.

16. Murthy SN, Cooper HS, Shim H, Shah RS, Ibrahim SA and Sedergran DJ: Treatment of dextran sulfate sodium-induced murine colitis by intracolonic cyclosporin. Dig Dis Sci 38: $1722-1734,1993$

17. Souza MM, Aguilar-Nascimento JE, Gomes-da-Silva MH and Carlos Junior R: Effects of budesonide and probiotics enemas on the colonic mucosa of rats with experimental colitis. Acta Cir Bras 22: 34-38, 2007.

18. Araki Y, Andoh A, Fujiyama Y and Bamba T: Development of dextran sulphate sodium-induced experimental colitis is suppressed in genetically mast cell-deficient $W_{s} / W s$ rats. Clin Exp Immunol 119: 264-269, 2000.

19. Gaudio E, Taddei G, Vetuschi A, Sferra R, Frieri G, Ricciardi G and Caprilli R: Dextran sulfate sodium (DSS) colitis in rats: Clinical, structural, and ultrastructural aspects. Dig Dis Sci 44 $1458-1475,1999$

20. Bürger M, Schmidt C, Teich N and Stallmach A: Medical therapy of active ulcerative colitis. Viszeralmedizin 31: 236-245, 2015

21. Cawthorpe D and Davidson M: Temporal comorbidity of mental disorder and ulcerative colitis. Perm J 19: 52-57, 2015

22. Wehkamp J, Götz M, Herrlinger K, Steurer W and Stange EF: Inflammatory bowel disease. Dtsch Arztebl Int 113: 72-82, 2016

23. Bannaga AS and Selinger CP: Inflammatory bowel disease and anxiety: Links, risks, and challenges faced. Clin Exp Gastroenterol 8: 111-117, 2015.

24. de Sousa Rodrigues ME, Bekhbat M, Houser MC, Chang J, Walker DI, Jones DP, Oller do Nascimento CM, Barnum CJ and Tansey MG: Chronic psychological stress and high-fat high-fructose diet disrupt metabolic and inflammatory gene networks in the brain, liver, and gut and promote behavioral deficits in mice. Brain Behav Immun 59: 158-172, 2017.

25. Moloney RD, O'Mahony SM, Dinan TG and Cryan JF: Stress-induced visceral pain: Toward animal models of irritable-bowel syndrome and associated comorbidities. Front Psychiatry 6: 15, 2015.

26. Wang SX and Wu WC: Effects of psychological stress on small intestinal motility and bacteria and mucosa in mice. World J Gastroenterol 11: 2016-2021, 2005.

27. Keefer L, Keshavarzian A and Mutlu E: Reconsidering the methodology of 'stress' research in inflammatory bowel disease. J Crohns Colitis 2: 193-201, 2008.

28. Golbidi S, Frisbee JC and Laher I: Chronic stress impacts the cardiovascular system: Animal models and clinical outcomes. Am J Physiol Heart Circ Physiol 308: H1476-H1498, 2015.
29. Shah E, Rezaie A, Riddle M and Pimentel M: Psychological disorders in gastrointestinal disease: Epiphenomenon, cause or consequence? Ann Gastroenterol 27: 224-230, 2014.

30. Radek KA: Antimicrobial anxiety: The impact of stress on antimicrobial immunity. J Leukoc Biol 88: 263-277, 2010.

31. Priyadarshini S and Aich P: Effects of psychological stress on innate immunity and metabolism in humans: A systematic analysis. PLoS One 7: e43232, 2012.

32. Rho SG, Kim YS, Choi SC and Lee MY: Sweet food improves chronic stress-induced irritable bowel syndrome-like symptoms in rats. World J Gastroenterol 20: 2365-2373, 2014.

33. Karl JP, Hatch AM, Arcidiacono SM, Pearce SC, PantojaFeliciano IG, Doherty LA and Soares JW: Effects of psychological, environmental and physical stressors on the gut microbiota. Front Microbiol 9: 2013,2018.

34. Stults-Kolehmainen MA and Sinha R: The effects of stress on physical activity and exercise. Sports Medl 44: 81-121, 2014.

35. Nirmal J, Babu CS, Harisudhan T and Ramanathan M: Evaluation of behavioural and antioxidant activity of Cytisus scoparius Link in rats exposed to chronic unpredictable mild stress. BMC Complement Altern Med 8: 15, 2008.

36. Kim TK, Park JY and Han PL: Physiological parameters in the blood of a murine stress-induced depression model before and after repeated passive exercise. Endocrinol Metab 30: 371-380, 2015.

37. Guo S, Gao Q, Jiao Q, Hao W, Gao X and Cao JM: Gastric mucosal damage in water immersion stress: Mechanism and prevention with GHRP-6. World J Gastroenterol 18: 3145-3155, 2012.

38. Padgett DA, Marucha PT and Sheridan JF: Restraint stress slows cutaneous wound healing in mice. Brain Behav Immun 12: 64-73, 1998.

39. Lechuga S and Ivanov AI: Disruption of the epithelial barrier during intestinal inflammation: Quest for new molecules and mechanisms. Biochim Biophys Acta Mol Cell Res 1864: 1183-1194, 2017.

40. Antoni L, Nuding S, Wehkamp J and Stange EF: Intestinal barrier in inflammatory bowel disease. World J Gastroenterol 20: $1165-1179,2014$

41. Marteau P, Colombel JF, Nemeth J, Vaerman JP, Dive JC and Rambaud JC: Immunological study of histologically non-involved jejunum during Crohn's disease: Evidence for reduced in vivo secretion of secretory IgA. Clin Exp Immunol 80: 196-201, 1990.

42. Reyna-Garfias H, Miliar A, Jarillo-Luna A, Rivera-Aguilar V, Pacheco-Yepez J, Baeza I and Campos-Rodríguez R: Repeated restraint stress increases IgA concentration in rat small intestine. Brain Behav Immun 24: 110-118, 2010.

43. Heffner KL: Neuroendocrine effects of stress on immunity in the elderly: Implications for inflammatory disease. Immunol Allergy Clin North Am 31: 95-108, 2011.

44. Meyer JS and Hamel AF: Models of stress in nonhuman primates and their relevance for human psychopathology and endocrine dysfunction. ILAR J 55: 347-360, 2014.

45. Gersemann M, Wehkamp J and Stange EF: Innate immune dysfunction in inflammatory bowel disease. J Intern Med 271: 421-428, 2012.

46. Aggarwal BB, Gupta SC and Sung B: Curcumin: An orally bioavailable blocker of TNF and other pro-inflammatory biomarkers. Br J Pharmacol 169: 1672-1692, 2013.

47. Luo SY, Le Z, Lv XH and Zhong ZG: Study on effect of total flavonoids of Oldenlendia difflusa on ulcerative colitis and its immunological mechanism Zhongguo Zhong Yao Za Zhi 39: 896-900, 2014 (In Chinese).

48. Sheridan JF, Dobbs C, Jung J, Chu X, Konstantinos A, Padgett D and Glaser R: Stress-induced neuroendocrine modulation of viral pathogenesis and immunity. Ann N Y Acad Sci 840: 803-808, 1998.

49. Slavich GM and Irwin MR: From stress to inflammation and major depressive disorder: A social signal transduction theory of depression. Psychol Bull 140: 774-815, 2014.

50. Peng YL, Wang WY, Jiang CL and Wang YX: Roles of cytokines in stress-induced depression. Sheng Li Xue Bao 65: 229-236, 2013 (In Chinese).

51. Ricklin D, Reis ES, Mastellos DC, Gros P and Lambris JD: Complement component C3-The 'Swiss Army Knife' of innate immunity and host defense. Immunol Rev 274: 33-38, 2016.

52. Sajadinejad MS, Asgari K, Molavi H, Kalantari M and Adibi P: Psychological issues in inflammatory bowel disease: An overview. Gastroenterol Res Pract 2012: 106502, 2012. 